$\begin{array}{ll}\text { Research Square } & \text { Preprints are preliminary reports that have not undergone peer review. } \\ \text { They should not be considered conclusive, used to inform clinical practice, } \\ \text { or referenced by the media as validated information. }\end{array}$

\title{
Selenium Biofortified Alfalfa Hay Supplemented to Dairy Heifers During the Peripartum Affects the Antioxidant Function of Albumin but Has Little Impact on Metabolic and Immune Function
}

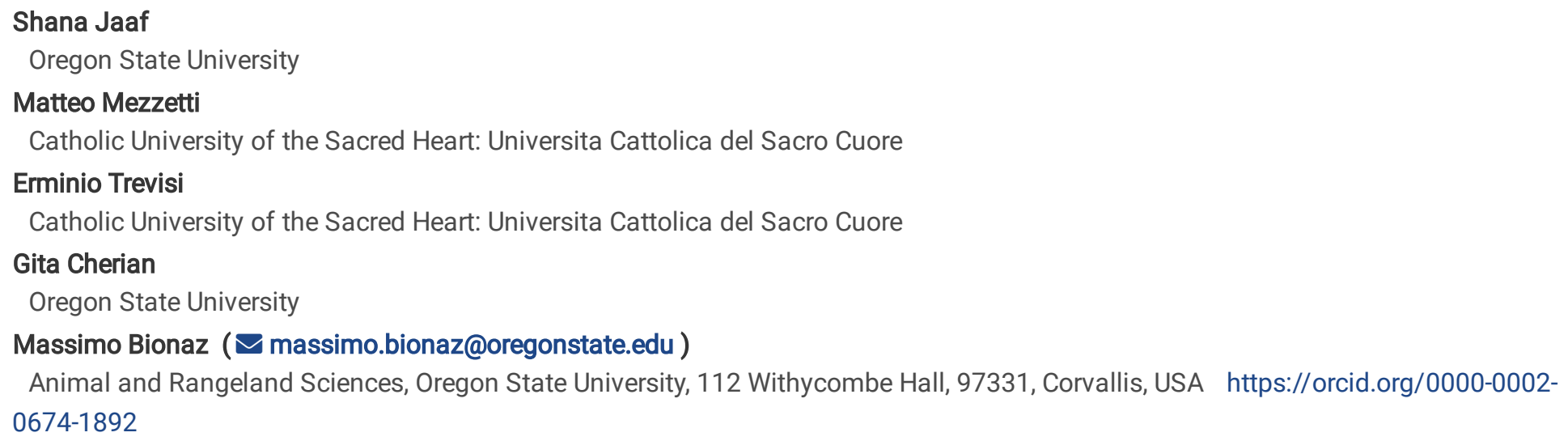

\section{Research}

Keywords: Selenium biofortified hay, blood parameter, oxidative stress, immune response, dairy heifers

Posted Date: November 24th, 2020

DOl: https://doi.org/10.21203/rs.3.rs-112033/v1

License: @ (1) This work is licensed under a Creative Commons Attribution 4.0 International License. Read Full License 


\section{Abstract}

Background: the peripartum is the most critical period in dairy cows with high incidence of diseases due to immune dysfunctions, often paired with systemic inflammation and oxidative stress. Selenium is a trace mineral that plays an important role in anti-oxidative function and immune response. We hypothesize that supplementing dairy cows with a relatively small amount of Se-biofortified hay during the last 40 days of pregnancy and early lactation improves performance, metabolism, oxidative status, and immune response.

Methods: ten Jersey and 8 Holstein pregnant dairy heifers were divided into two groups and supplemented with $1 \mathrm{~kg} / 100 \mathrm{~kg}$ BW of Sebiofortified (Sel; $n=9 ; 3.2 \mathrm{ppm} \mathrm{Se}$ ) or non-biofortified (Ctr; $n=9 ; 0.4 \mathrm{ppm} \mathrm{Se}$ ) alfalfa hay from 40 days prior- to 2 weeks post-partum. Heifers were monitored daily for feed intake, activity, and milk yield, and weekly for BW and BCS. Milk samples were assessed for components and fatty acid profile. Blood samples were collected regularly to assess metabolic, oxidative, and inflammatory biomarkers, and to evaluate leukocytes phagocytosis and differential through flow cytometry.

Results: supplementation of Se biofortified hay did not affect feed intake, milk yield, BW, BCS, milk components, and any of the parameters measured on leukocytes but increased the hematocrit. Animal receiving Se biofortified hay had larger concentration of plasma albumin and a tendency for larger blood urea, indicating a possible better liver status, especially post-partum. None of the parameters measured in plasma related to the oxidative status were affected, except the concentration of advanced oxidation protein products that was greater in Sel vs. Ctr. The concentration of advanced oxidation protein products was negatively correlated with parameters related to inflammation but positively associated to plasma albumin suggesting a possible improved anti-oxidative function of circulating albumin by Se-biofortified hay supplementation.

Conclusions: feeding Se-biofortified hay during pregnancy in dairy heifers had little effect on metabolic, inflammatory, and oxidative status parameters with no effect on performance or immune response. Supplementation with Se-biofortified hay increased plasma level of albumin, possibly as consequence of improved liver function, promoting the antioxidant role of albumin as indicated by increased AOPP.

\section{Background}

The most critical period in the life of a dairy cow is the "transition period," which is defined as three weeks before and three weeks after parturition [1]. During that time, high-producing dairy cows undergo many physiological and metabolic changes [2]. The high nutritional requirements of lactation, together with the inability to eat enough, drive the cow into a negative energy balance that elicits the mobilization of non-esterified fatty acids (NEFA) from the adipose tissue.

A large amount of circulating NEFA typical of early post-partum cows when entering the hepatocytes can contribute to increasing reactive oxygen species (ROS) during the process of being converted to energy in the mitochondria [2-4]. ROS are not only produced by catabolism of NEFA but also by active phagocytes [5]. An imbalance between the high production of ROS and low antioxidant defenses generate oxidative stress [6]. Early post-partum dairy cows also experience inflammatory-like conditions that can negatively affect the ability of the liver to face the ensuing large metabolic and immune challenges $[7,8]$. All the above causes increase in the incidence of diseases $[9,10]$.

The metabolic and oxidative stress experienced by dairy cows during the transition period negatively impact the immune system [11]. However, immune dysfunction early post-partum in dairy cows is also highly determined by nutritional deficiencies, as demonstrated by the positive effects on the immune system by various supplements during this stage of lactation $[12,13]$. Among trace minerals, Se supplementation can enhance the antioxidative status and the innate and adaptive immune response [14-16]. Se supplementation can also affect overall inflammatory response and metabolism [14].

Selenium is deficient in forages produced in several parts of the world, including NW US, due to the low Se availability in the soil [17]. Thus, cows do not receive an adequate amount of Se from forages, and supplementation is required. It is difficult to reach the requirements of Se in dairy cows using inorganic Se supplementation, which is mostly due to the acute toxicity of high doses of inorganic Se. For this reason, Se is the only micronutrient regulated as a feed additive by the FDA that sets the limit of Se supplementation in cattle to $0.3 \mathrm{ppm}$ in various supplements with a maximum of $3 \mathrm{mg} / \mathrm{head}$ per day [18].

Compared to inorganic Se (i.e., selenate and selenite), the organic Se (i.e., seleno-amino acids) is less toxic to cattle and can be used as a supplement to match the requirement of $\mathrm{Se}$ in this species $[19,20]$. Se-yeast has been successfully used as supplement in pregnant 
Jersey cows [14]. Besides Se-yeast, agronomic biofortification of forages with Se can be an excellent alternative to supplement Se in high producing dairy cows fed forages grown in areas with low Se in the soil [21-23].

We have performed a study where we fed dairy heifers during the last 40 days of pregnancy until 14 days in milk with a relatively low amount of Se-biofortified hay (1 kg DM/100 kg BW) [24]. In that study, the treatment improved Se status and the glutathione peroxidase (GPX) activity in whole blood and plasma. However, the effect of Se-biofortified alfalfa on metabolism, overall oxidative status, immune status, and performance was not assessed.

Based on prior observations of the effect of organic Se in dairy cows, we hypothesize that supplementing dairy cows with a relatively small amount of Se-biofortified hay during the dry period and early lactation improves performance, metabolism, oxidative status, and immune response. The objective of the present study was to evaluate the effect of feeding $1 \mathrm{~kg} / 100 \mathrm{~kg}$ BW of Se-biofortified alfalfa to pregnant dairy heifers during the last 40 days of pregnancy and early lactation on blood biomarkers, performance, and immune status.

\section{Methods}

\section{Animals, ration, and experimental design}

The overall experimental design is shown in Additionla File 1 Figure S1. Details of the experiments and nutritive values of the diets are reported elsewhere [24]. Briefly, ten Jersey and eight Holstein pregnant heifers were kept in a pen equipped with Calan gates received either $1 \mathrm{~kg} / 100 \mathrm{~kg}$ BW of Se-biofortified alfalfa hay (Sel; $3.25 \mathrm{mg} \mathrm{Se} / \mathrm{kg} \mathrm{DM}$ ) or control hay (Ctr, $0.43 \mathrm{mg} \mathrm{Se} / \mathrm{kg} \mathrm{DM}$ ) starting at 40 day from expected parturition to 14 day in milk (DIM). Animals were milked twice daily at 0500 and $1800 \mathrm{~h}$ and fed ad-libitum a total mixed ration (TMR) twice daily at 0700 and 1900. Before feeding, TMR was mixed by hand with the chopped Se-biofortified alfalfa hay or the control alfalfa hay. Details of the feeding and composition and chemical analysis of the feedstuffs were reported previously [24].

\section{Feed intake, body weight, and body condition score}

Dry matter intake (DMI) was recorded daily by measuring feed provided and residuals. The BW was measured once a week with a walkin scale (Afimilk, Kibbutz Afikim, Israel Israel). The body condition score (BCS) was measured every week by three different people, using a 1 to 5 scale. The final BCS was calculated as the geometrical mean of the three operators.

\section{Activity steps, milk yield, milk components, and milk fatty acid profiling}

The activity steps of the animals, milk yield and milk conductivity were measured by the Afimilk system. Milk samples were collected in tubes containing bronopol during morning milking at 3, 7, and 14 DIM and shipped to a commercial laboratory (Willamette National Dairy Herd Information Association, Salem, OR) for analysis of butterfat, protein, lactose, solid non-fat (SNF), milk urea nitrogen (MUN), and somatic cell count (SCC). Milk fatty acid profile was analyzed in milk samples collected at 7 and 14 DIM using gas chromatography as previously described [25] using behenic acid as the internal standard (100 $\mu \mathrm{L}$ of a $0.2 \mathrm{mg} / \mathrm{mL}$ solution, Cat\#1161, Matreya, LLC).

\section{Blood collection and analyses}

Blood samples were collected before the morning feeding from the jugular vein into evacuated tubes with Na-heparin (Cat\# 366480, $10 \mathrm{~mL}$; Becton Dickinson, Franklin Lakes, NJ) at $-39 \pm 5$ (i.e., baseline), $-27 \pm 4,-10 \pm 3,-2 \pm 1,1 \pm 0,2 \pm 0,4 \pm 1,7 \pm 1$ and $14 \pm 1$ DIM. Aliquots of plasma were sent to the Department of Animal Sciences, Food and Nutrition (DIANA), Università Cattolica del Sacro Cuore, Piacenza, Italy for metabolic and inflammatory profiling. Blood samples were processed and analyzed following the methods previously described [26]. Energy, protein, and mineral metabolism were profiled by measuring the concentration of glucose, cholesterol, NEFA, beta-hydroxybutyric acid (BHB), urea, and total protein, globulin, $\mathrm{Ca}$, and $\mathrm{Mg}$. Positive acute-phase proteins such as haptoglobin and ceruloplasmin and negative acute-phase proteins such as albumin and paraoxonase were used to evaluate the inflammatory response. Myeloperoxidase (MPO) was determined to assess the activity of neutrophils. Liver activity and health were assessed measuring total bilirubin, aspartate aminotransferase, $\gamma$-glutamyl transferase, and alkaline phosphatase (ALP). The oxidative stress was monitored by measuring total reactive oxygen metabolites, thiolic groups, ferric reducing antioxidant power, and advanced oxidation protein products (AOPP). The kidney function was assessed via plasma creatinine. Several ratios between parameters were computed. The NEFA to albumin ratio $(\mathrm{mM} / \mathrm{mM})$ was used to assess potential toxicity of free fatty acids (normal range is 0.5-1) [27]. The AOPP to albumin ratio was used as an index of protein oxidation (larger number indicates higher oxidation) [28]. The albumin to globulin ratio was used as an index of nutrition and systemic inflammatory status (the larger the number, the better the nutritional and 
inflammatory status) [29]. The urea to creatinine ratio was used as an indirect index of the renal glomerular filtration rate with a normal range of $40-100(\mathrm{mM} / \mathrm{mM})$, with ranges $>100$ indicating extra-renal problems, such as dehydration, and values $<40$ indicating kidney issues $[30,31]$.

\section{Carrageenan skin test}

The carrageenan skin test for the assessment of the in vivo diapedesis was done as previously described [32] at $-47 \pm 5$ (baseline), -19 $\pm 4,-3 \pm 2$, and $7 \pm 1$ DIM. Data from four Jersey cows, two from the Sel and two from the Ctr groups were unavailable. Briefly, sterile carrageenan ( $\mathrm{k}$-Carrageenan, Cat\# IC10488680, VWR, USA) was dissolved in sterile saline (Cat\# VINV-SALN-1000, Henry Schein, USA) to obtain a $0.7 \%$ solution. The CST was administered by subcutaneous injection of $0.6 \mathrm{~mL}$ of carrageenan solution (equal to $4.2 \mathrm{mg}$ of carrageenan) after clipping the hair of the area of the shoulder. The injection was done alternatively in the left and right shoulder between time points and the site of treatment was different for each injection repeated in the same shoulder. The skin thickness was measured using a skinfold caliper (Cat\# 470119-588, VWR, USA) immediately before carrageenan injection ( 0 days), then at 2 and 9 days after the injection. The overall response was calculated as the area under the curve of the thickness measured at day 2 and day 9 , subtracting the thickness measured at day 0 .

\section{Leukocytes counting, phagocytosis, and differential}

Total leukocytes were counted using the Leuko-tic blue kit (Cat\#4013-0006/-0007/-0008, bioanalytical, Germany). Phrodo BioParticles Phagocytosis kit containing green S. aureus bioparticles (Cat\# P35382, Life Technologies) was used to measure leukocytes phagocytosis according to the manufacturer's protocol. At the end of the protocol, cells were stained with primary antibodies CAM36A (IgG anti-CD14; Cat\# 6-9-03) and CH138A (IgM; neutrophils marker; Cat\# 2001) from the Washington State University Monoclonal Antibody Center (Pullman, WA). Allophycocyanin goat anti-mouse IgG (Cat\# M30005, Caltag Laboratories) and R-Phycoerythrin goat anti-mouse lgM (Cat\# 662587, Invitrogen) were used as secondary antibodies. Final samples were filtered using a cheesecloth and loaded on a 96 well flat-bottomed plate (Cat\#655 180, Cellstar, USA) for flow cytometer assay using a Beckman Coulter CytoFLEX. Protocol for cell preparation/staining and flow cytometer data for phagocytosis and differential were performed as previously described [33].

\section{Statistical analysis}

Milk production was analyzed as daily milk yield during the first 14 DIM and as a weekly average for the first 120 DIM. When available, data were arithmetically corrected using the baseline for each breed separately as previously described [33] to obtain the same mean between treatment groups at baseline but keep the differences between breeds. After the correction, the baseline was removed from the statistical model. Statistical analysis was performed using SAS (v9.4, SAS Institute, Inc., Cary, NC, USA). For all parameters, outlier data were checked using PROC REG. Data with a studentized $t>3.0$ were removed. Data were analyzed by GLIMMIX with the fixed effect of feeding Se biofortified hay (Se), breed (Br), time, and their interactions with the cow as a random effect using the default covariate model (variance components). The Kenward-Roger degrees of freedom approximation was used. For milk fatty acid analysis, a PROC GLM was used. PROC CORR was used for correlation analysis among the variables. Differences were considered significant with P $\leq$ 0.05 and a tendency with $P \leq 0.10$.

\section{Results}

\section{Performance and milk composition}

None of the performance data were significantly affected by feeding Se biofortified alfalfa hay (Table 1). An exception was the lactose yield, which increased by feeding Se-biofortified hay to Holstein but had the opposite effect on Jersey cows. This effect also drove a tendency $(P=0.06)$ for the same pattern for SNF. Milk yield and SCC also tended to be affected by the treatment. Milk yield during the first 120 DIM had a tendency $(P=0.07)$ to be affected by SexBrxTime interaction driven by a larger increase through time in Holstein cows in Sel vs. Ctr (Additional File 1 Figure S2). The SCC tended ( $P=0.08)$ to increase in Jersey cows in Sel but decreased in Holstein cows in the Sel group compared to their relative control groups.

Feeding Se-biofortified hay had a minor effect on fatty acid profiling of the milk. Only the proportion of the peak corresponding to the sum of trans13-C18:1 and trans14-C18:1 was significantly increased by Se-biofortified hay (Additional File 2 Table S1). The $\Delta 9$ desaturation activity toward C14:0 and proportion of C20:3 n3 had a significant interaction SexTime due to a decrease from 7 to 14 DIM in Sel but an increase in Ctr cows and the proportion of conjugated linolenic acid (C18:3CLN) was affected by a full interaction 
SexBrxTime due to a larger value at 7 DIM in Jersey cows receiving the Se biofortified hay compared to Ctr (Additional File 1 Figure S1).

\section{Plasma parameters}

All the parameters measured in plasma are reported in Table 2. The temporal pattern of parameters with a significant effect is shown in Figure 1.

Metabolic parameters. None of the measured parameters related to metabolism were significantly affected by feeding Se-biofortified hay in peripartum heifers. A tendency $(\mathrm{P}=0.06)$ for larger concentration of blood urea in Sel vs. Ctr cows was detected.

Inflammatory parameters. A significant SexTime and SexBrxTime interactions were detected for the negative acute-phase protein albumin (Figure 1A). There was significantly greater concentration of circulating albumin at 14 DIM in Sel vs. Ctr. A tendency for a full interaction $(P=0.06)$ was detected for the positive acute-phase protein haptoglobin, but there was not a clear effect of the Se biofortified hay in any of the time points evaluated (Figure 1B). We also detected a tendency $(P=0.10)$ for higher concentration of plasma MPO in Sel vs. Ctr.

Liver status. Only ALP was affected by the full interaction between SexBrxTime, but there was no difference due to the Se biofortified hay in the time points evaluated (Figure 1C).

Oxidative status. Of all parameters measured related to the oxidative status, only the plasma concentration of AOPP was overall greater in Sel vs. Ctr cows (Figure 1D). The AOPP to albumin ratio was larger in Sel vs. Ctr.

Minerals. Plasma concentration of $\mathrm{Ca}$ (Figure 1E) and estimated free Ca was affected by a full interaction of Sel×Br×Time due to larger values in Sel vs. Ctr in Jersey cows at -10 DIM but larger values in Sel vs. Ctr in Holstein cows at 14 DIM. Mg was decreased by Sebiofortified hay prior parturition only in Holstein cows (Figure 1F).

Kidney function. The urea to creatinine ratio was larger in Sel vs. Ctr cows with not differences in plasma concentration of creatinine.

Other parameters. The hematocrit was overall larger in Sel vs. Ctr cows (Figure 1G). The concentration of blood total protein tended $(P=0.08)$ to be increased by the treatment while globulin tended $(P=0.06)$ to be affected by the treatment based on breed, with a numerical increase in Jersey cows while decreased in Holstein cows fed Se-biofortified hay vs. control.

\section{Immunological parameters}

None of the measured immune-related parameters, including phagocytosis, leukocytes differential, and CST, were affected by the Se treatment (Table 3); however, the leukocytes count was affected by the full interaction, due to a sudden drop early post-partum with a quick increase afterwards in Holstein cows fed with Se biofortified hay compared to the other groups (Figure 1H).

\section{Correlations of AOPP with other parameters}

Due to the unexpected pattern of AOPP, a correlation between AOPP and other parameters in our study was performed as well as the correlation between all the measured parameters (Additional File 3). Plasma level of AOPP in our study was not correlated with any of the immune-related parameters and negatively correlated $(P<.001)$ with plasma GPx $(r=-0.46)$, total ROM $(r=-0.41)$, inflammatory parameters haptoglobin and ceruloplasmin $(r=-0.38)$, NEFA $(-0.36)$, BHB $(r=-0.31)$, or indexes of poor liver activity/health such as AST/GOT $(r=-0.47)$ and total bilirubin $(r=-0.28)$. The plasma level of AOPP was instead positively correlated $(r>0.32 ; P<.0001)$ with parameters related to low inflammation and/or good liver function such as albumin, cholesterol, and paraoxonase. Levels of thiol groups and albumin were positively correlated $(r=0.60 ; P<.0001)$ while no correlations were existed between the activity of GPx in whole blood previously measured [24] with hematocrit.

\section{Discussion}

Cow performance was not affected by Se-biofortified hay

Previous studies on peripartum ewes lambs indicated a positive effect of Se supplementation during pregnancy on mammary gland growth, development, and vascularity $[34,35]$ that can increase milk production. In our study, only a tendency for increased milk 
production during the first 120 days of lactation in primiparous Holstein cows was detected and not in Jersey cows, but, except for lactose which increased in Holstein but decreased in Jersey cows receiving the Se-biofortified hay, none of the milk components were affected by the treatment. Our findings are similar to prior studies where Se supplementation did not affect milk yield and composition $[36,37]$, but, as in our study, the same treatment increased the lactose yield in Holstein dairy cows [37]. Different than those prior studies and our study, in another study it was observed a significant increase in fat \% in lactating multiparous cows supplemented with Se-yeast compared to cows supplemented with inorganic Se [20].

In prior studies, Se supplementation increased the proportion of polyunsaturated fatty acids (PUFA) in the milk of cows [38] and humans [39]. It is thought that the effect of Se on PUFA is due to its role via GPx enzyme. The GPx can prevent the oxidation by free radicals of PUFA present in milk [40]. Contrary to the above experiments, we did not detect any important effect on milk PUFA by feeding Se-biofortified hay. This appears to be consistent with our data indicating that feeding Se-biofortified hay does not affect milk GPx activity [24].

Selenium biofortified hay improves albumin production by the liver

In our experiment, supplementation of dairy cows with Se-biofortified hay improved plasma albumin concentration early post-partum. Similar results were detected previously in Jersey cows supplemented with Se-yeast during the last eight weeks of gestation [14] and in Holstein cows supplemented with selenomethionine from 21 days prepartum to 21 days post-partum [41] or inorganic Se + vitamin E [42].

The reason for the consistent higher concentration of circulating albumin when organic Se is provided to cattle is unclear. Albumin is a negative acute-phase protein, and larger increase in circulating albumin is consequence of lower inflammation and better liver function [11]. In our experiment, we did not observe any effect of the treatment on inflammation; thus, the larger plasma albumin in Se-treated cows cannot be the consequence of lower inflammation. The reason for the greater albumin observed in our experiment by feeding Sebiofortified hay is likely due to an increase in liver synthesis of albumin or decreased turnover. Unfortunately, we did not measure synthesis of albumin, but preliminary data indicate not effect of feeding Se-biofortified hay on the transcription of albumin gene in the liver [43].

Urea concentration in plasma is the result of the balance between urea input (i.e., produced by the liver) and output (i.e., rumen utilization, elimination by the kidneys, and passive loss via feces, sweat, and milk) [44]. Hence, increased plasma urea can be caused by increased urea production, decreased urea elimination, or a combination of the two. We can exclude the increase of urea by dietary protein intake considering that there was no difference in DMI and dietary crude protein between groups [24]. We can also eliminate any kidney problem, considering that larger urea to creatinine ratio in cows supplemented with Se-biofortified hay was detected. The higher urea to creatinine ratio however suggests a larger reabsorption of urea by the kidney in Sel vs. Ctr cows. Urea in plasma can also increase as a consequence of increased muscle proteolysis [45]. This does not appear to be the case in our study due to the lack of any difference in BW between treatment groups. Thus, it is possible that the larger urea in the blood was the consequence of a combined improved capacity of the liver to synthesize urea and larger re-absorption of urea by the kidney. Data produced in vitro [46] and in vivo [47] demonstrated a positive effect of organic Se supplementation on rumen fermentation in dairy cows. Thus, it is possible that the larger concentration of plasma urea observed in our study was also due to greater production of microbial proteins. However, this did not translate in more milk protein synthesis. In the in vivo study, Wei and collaborators detected a linear reduction of ammonia in the rumen by an increased dose of organic Se supplemented. This would indicate a larger amount of ammonia utilization by the microbes that would decrease the urea production by the liver. Thus, the observed effect on urea level by Se-biofortified hay remains still unclear.

To further complicate the interpretation of the urea data, an increase in blood urea concentration in Se supplemented animals was also observed in rats supplemented with inorganic Se [48] and in one year old Angus steers fed organic Se [49] but not in multiparous dairy cows $[41,50]$. Thus, it is possible that the observed increased circulating urea by feeding Se-biofortified hay might only be associated with the young age of the cows used.

Overall, the higher albumin and urea concentration in plasma appears to partly support a liver in better condition in cows treated with Se-biofortified hay compared to cows fed a normal hay. It is also possible that the effects observed were due to a better rumen fermentation or larger kidney re-absorption of urea. Finally, the effect can be also associated with the use of young animals.

Selenium biofortified hay does not affect the oxidative status and the immune system but improves the antioxidant function of albumin 
One of the main antioxidant enzymes in the blood of cows is the Se-dependent GPx that acts to remove free radicals normally produced by cells [51]. The activity of GPx was increased significantly in erythrocytes and plasma of the cows supplemented with Sebiofortified hay compared to control cows in our experiment [24], indicating an enhanced antioxidant response. However, none of the measured parameters associated with the oxidative status reported in the present manuscript were affected by the treatment with the exception of the AOPP, that was larger in cows few Se-biofortified hay compared to control animals.

The AOPP is a marker of protein oxidation that was first described in the plasma of uremic human patients [52], and it has been recognized as a marker of inflammation in several diseases in humans [53]. Higher concentration of AOPP in plasma was also observed in dairy cows experiencing endometritis [54]. AOPP are products of proteins exposed to free radicals, and they are formed by the reaction between plasma proteins and chlorinated oxidants mediated by the neutrophil enzyme MPO $[55,56]$. AOPP can also trigger the oxidative burst and the synthesis of inflammatory cytokines in neutrophils and monocytes [57]. Increased chemotaxis and respiratory burst of neutrophils was detected in sheep supplemented with Se nanoparticles compared to sodium selenite [58]. Unfortunately, we did not measure respiratory burst capacity in neutrophils in our experiment, but MPO activity tended to be larger in cows supplemented with Se-biofortified hay. Despite being both overall larger in Sel vs. Ctr, the negative correlation between AOPP and MPO and AOPP to albumin ration and MPO do not support a role of MPO in determining the level of AOPP in our study. In humans, a positive correlation between levels of AOPP and MPO was observed in plasma but only in patients with kidney failure and not in healthy patients [59]. Our cows, including the ones fed with Se biofortified hay groups, were all healthy with no kidney problems as supported by the normal level of creatinine; thus, the lack of correlation between AOPP and MPO in healthy animals appears to be confirmed.

The above data do not explain the larger concentration of plasma AOPP detected in animals treated with Se-biofortified hay compared to control cows in our study. Interestingly, the negative correlation of AOPP with inflammatory parameters and indexes of poor liver activity/health and the positive correlation with parameters related to low inflammation and/or good liver function suggest higher AOPP in plasma as a positive outcome.

Serum albumin is one of the major antioxidant proteins in the blood [60]. Interestingly, the results of albumin oxidation are AOPP [61]. The AOPP produced from oxidized albumin bind to high-density lipoprotein scavenger receptor and are primarily eliminated by the liver and the spleen [62]. Thus, the larger concentration of AOPP can partly be explained by the greater amount of circulating albumin in cows fed Se-biofortified hay. This is also supported by the positive correlation between plasma levels of albumin and AOPP. In albumin, methionine ( $0.8 \%$ of all amino acids) and cysteine (5.8\%) account for up to $80 \%$ of its total antioxidant activity [63]. The thiol group Cys34 in albumin that acts as a scavenger for reactive oxygen and nitrogen species accounts for $80 \%$ of the reduced thiols in human plasma.

Our data appear to suggest, contrary to prior data, that larger concentration in plasma of AOPP is associated with lower inflammation and/or better oxidative status. Due to this apparent contradiction with the classical interpretation of higher oxidation by a larger level of AOPP, the role of AOPP in dairy cows deserve further investigations.

The increase in GPx activity but lack of effect of Se-biofortified hay on other parameters of the oxidative status in our study is very similar to a recent study reported in pregnant heifers [64]. In that study, heifers were supplemented with hydroxy-selenomethionine during the prepartum, and the authors observed in blood a significantly larger GPx activity but no effect on the lipid peroxidation marker malondialdehyde. However, our results differ substantially with another recent study performed in multiparous cows [16]. In that study, supplementation of organic Se prepartum improved most of the antioxidant parameters measured, most of them assessed also in our study. Thus, it is very likely that the lack of effects observed in our study was due to the use of pregnant heifers instead of using multiparous cows.

Selenium-biofortified hay affects $\mathrm{Ca}$ and $\mathrm{Mg}$ metabolism

The effect on the concentration of serum Ca by feeding Se-biofortified hay can partly be driven by the known relationship between albumin and $\mathrm{Ca}$ since $\mathrm{Ca}$ ions (approx. $50 \%$ of the total serum $\mathrm{Ca}$ ) is bound in blood to albumin [65]. However, the free Ca appears to be positively associated with Se-biofortified hay supplementation prepartum in Jersey cows. This is of importance, considering that this is the active form of $\mathrm{Ca}$, that when decreased induces the release of parathyroid hormone via the $\mathrm{Ca}^{2+}$ sensing receptor, controlling the Ca homeostasis [66]. Ca homeostasis prepartum is of paramount importance in dairy cows, especially Jersey cows, which are known to be more at risk of this post-partum hypocalcemia. Probably even more important for the prevention of hypocalcemia is the level of $\mathrm{Mg}$ in plasma prepartum. As a cofactor in parathyroid hormone action, $\mathrm{Mg}$ is required for the efficient absorption and resorption of Ca; hence,

Page 7/18 
cows with low blood magnesium around calving are more prone to get milk fever [67]. Our data indicated a higher Ca prepartum in Jersey cows and a lower Mg during the first 2 DIM, suggesting a higher risk of milk fever. However, none of our cows had milk fever. Thus, the effect of Se-biofortified on $\mathrm{Ca}$ and $\mathrm{Mg}$ is of interest, but the consequences remain unclear.

Selenium biofortified hay improves red blood cells

The hematocrit was positively affected by feeding Se-biofortified hay in our study. This was not caused by dehydration as supported by the lack of change in plasma concentration of creatinine. While there are no previous data concerning cows, Se supplementation increase hematocrit in mice [68] and fattening lamb [69]. Selenium has a role in regulating red cell homeostasis by mitigating oxidative stress-dependent modulation of genes that affect the differentiation of erythroid progenitors [68]. Furthermore, oxidative stress is known to decrease the function and the half-life of red blood cells [70]. Se supplementation can prevents erythrocyte lysis and formation of methemoglobin by improved GPx activity, as observed in vitro in the rat [71]. However, the lack of correlation between the activity of GPx in whole blood previously measured [24] with hematocrit does not support the higher GPx activity in blood and plasma of cows supplemented with Se-biofortified hay improved erythropoiesis and/or protected red blood cells.

\section{Limitations Of The Study}

Our study presents several limitations. The number of animals used was low, and the two breeds had an unbalanced number of animals between the treatments. Another limitation was the use of pregnant heifers instead of multiparous cows. Thus, it is possible that a beneficial effect of the Se supplementation was not detected due to the use of young and healthy animals. The short term of data collection after parturition (14 days), especially milk components, was also a limitation of the study. This is suggested by the tendency for larger milk yield in Holstein cows when observed for 120 days post-partum.

\section{Conclusions}

The present study revealed that feeding pregnant heifers with a relatively low amount of Se-biofortified hay did not influence cow's performance or milk yield or composition, including the fatty acid profile of the butterfat. The treatment also had little effect on metabolic and inflammatory parameters. Furthermore, despite higher GPx activity in blood and plasma [24], no other measured parameters related to antioxidant response were affected. However, data allowed us to infer that supplementation of pregnant heifer with Se-biofortified hay likely improved the antioxidant function of albumin and improved erythropoiesis. All those outcomes need to be further validated. As indicated above, a lack of stronger effect might be due to the use of pregnant heifers and the low number of animals. It appears sensible to test further the effect of Se-biofortified hay in pluriparous cows. If a new experiment should be performed, our data indicate that the respiratory burst should be inserted among the measured parameters. More studies may be needed to conduct to clarify the main function of AOPP in dairy cows and their association with albumin and oxidative status.

\section{List Of Abbreviations}

ALP, alkaline phosphatase

AOPP, advanced oxidation protein products

BCS, body condition score

BHB, beta-hydroxybutyric acid

DIM, day in milk

DMI, dry matter intake

GPx, glutathione peroxidase

MPO, myeloperoxidase

MUN, milk urea nitrogen

NEFA, non-esterified fatty acids 
PUFA, polyunsaturated fatty acids

ROS, reactive oxygen species

SCC, somatic cell count

SNF, solid non-fat

TMR, total mixed ration

\section{Declarations}

Ethics approval and consent to participate

Experimental procedures used in this study were approved by the Institutional Animal Care and Use Committees of Oregon State University (protocol\# 4894).

\section{Availability of data and materials}

The datasets used and/or analyzed during the current study are available from the corresponding author on reasonable request.

\section{Competing interests}

The authors declare that they have no competing interests

\section{Funding}

The project was performed with fund provided by the Agriculture Research Foundation for the competitive grant program $2017-2019$ and by the USDA .Animal Health Project Number ORE00174

\section{Authors' contributions}

ET analyzed the blood samples, helped interpreting the data, and contributed to the final manuscript; GC helped with fatty acid analysis and contributed to the final manuscript; MB formulated the hypothesis and helped writing the manuscript; MM helped performing the experiment, analyzed the samples, and helped to write the manuscript; SJ performed the experiment, analyzed the samples, and wrote the manuscript. All authors read and approved the final manuscript

\section{Acknowledgements}

The authors would like to thank Seth Spencer, Larissa Lee McGuire, and Jeff Behm at OSU Dairy Research Center for their support during the research project.

\section{References}

1. Drackley JK: ADSA foundation scholar award. Biology of dairy cows during the transition period: the final frontier? J Dairy Sci 1999, 82(11):2259-2273.

2. Sordillo LM, Aitken SL: Impact of oxidative stress on the health and immune function of dairy cattle. Veterinary Immunology and Immunopathology 2009, 128(1-3):104-109.

3. Mordak R, Anthony SP: Periparturient stress and immune suppression as a potential cause of retained placenta in highly productive dairy cows: examples of prevention. Acta veterinaria Scandinavica 2015, 57(1):84-84.

4. Abuelo A, Alves-Nores V, Hernandez J, Muiño R, Benedito JL, Castillo C: Effect of Parenteral Antioxidant Supplementation During the Dry Period on Postpartum Glucose Tolerance in Dairy Cows. Journal of Veterinary Internal Medicine 2016, 30(3):892-898.

5. Knight JA: Review: Free radicals, antioxidants, and the immune system. Annals of Clinical and Laboratory Science 2000, 30(2):145158.

6. Trevisan M, Browne R, Ram M, Muti P, Freudenheim J, Carosella aM et al: Correlates of markers of oxidative status in the general population. American journal of epidemiology 2001, 154(4):348-356. 
7. Trevisi E, Jahan N, Bertoni G, Ferrari A, Minuti A: Pro-inflammatory cytokine profile in dairy cows: Consequences for new lactation. Italian Journal of Animal Science 2015, 14(3):285-292.

8. Bertoni G, Trevisi E, Han X, Bionaz M: Effects of Inflammatory Conditions on Liver Activity in Puerperium Period and Consequences for Performance in Dairy Cows. Journal of Dairy Science 2008, 91(9):3300-3310.

9. Sordillo LM, Mavangira V: The nexus between nutrient metabolism, oxidative stress and inflammation in transition cows. Animal Production Science 2014, 54(9):1204-1214.

10. O'Rourke D: Nutrition and udder health in dairy cows: A review. Irish Veterinary Journal 2009, 62(4):15-20.

11. Trevisi E, Minuti A: Assessment of the innate immune response in the periparturient cow. Res Vet Sci 2018, 116:47-54.

12. Spears JW: Micronutrients and immune function in cattle. Proceedings of the Nutrition Society 2000, 59(4):587-594.

13. Ingvartsen KL, Moyes K: Nutrition, immune function and health of dairy cattle. Anima/ 2013, 7(SUPPL.1):112-122.

14. Hall JA, Bobe G, Vorachek WR, Kasper K, Traber MG, Mosher WD et al: Effect of Supranutritional Organic Selenium Supplementation on Postpartum Blood Micronutrients, Antioxidants, Metabolites, and Inflammation Biomarkers in SeleniumReplete Dairy Cows. Biological Trace Element Research 2014, 161(3):272-287.

15. Mehdi Y, Dufrasne I: Selenium in cattle: A review. Molecules 2016, 21(4).

16. Gong J, Xiao M: Effect of Organic Selenium Supplementation on Selenium Status, Oxidative Stress, and Antioxidant Status in Selenium-Adequate Dairy Cows During the Periparturient Period. Biol Trace Elem Res 2018, 186(2):430-440.

17. U.S. Geological Survey: Selenium in Counties of the Conterminous Stat. In.; 2018.

18. NRC: Requirements of Dairy Cattle Seventh Revised Edition , 2001; 2001.

19. Salman S, Dinse D, Khol-Parisini A, Schafft H, Lahrssen-Wiederholt M, Schreiner $M$ et al: Colostrum and milk selenium, antioxidative capacity and immune status of dairy cows fed sodium selenite or selenium yeast. Archives of Animal Nutrition 2013, 67(1):48-61.

20. Oltramari CE, Pinheiro MdG, de Miranda MS, Arcaro JRP, Castelani L, Toledo LM et al: Selenium sources in the diet of dairy cows and their effects on milk production and quality, on udder health and on physiological indicators of heat stress. Italian Journal of Animal Science 2014, 13(1):48-52.

21. Hall JA, Bobe G, Vorachek WR, Hugejiletu, Gorman ME, Mosher WD et al: Effects of feeding selenium-enriched alfalfa hay on immunity and health of weaned beef calves. Biological Trace Element Research 2013, 156(1-3):96-110.

22. Hall JA, Harwell AM, Van Saun RJ, Vorachek WR, Stewart WC, Galbraith ML et al: Agronomic biofortification with selenium: Effects on whole blood selenium and humoral immunity in beef cattle. Animal Feed Science and Technology 2011, 164(3-4):184-190.

23. Novoselec J, Klir Ž, Domaćinović M, Lončarić Z, Antunović Z: Biofortification of feedstuffs with microelements in animal nutrition. Poljoprivreda 2018, 24(1):25-34.

24. Jaaf S, Batty B, Krueger A, Estill CT, Bionaz M: Selenium biofortified alfalfa hay fed in low quantities improves selenium status and glutathione peroxidase activity in transition dairy cows and their calves. $J$ Dairy Res 2020, 87(2):184-190.

25. Jaaf S, Rosa F, Moridi M, Osorio JS, Lohakare J, Trevisi E et al: 2,4-Thiazolidinedione in Well-Fed Lactating Dairy Goats: I. Effect on Adiposity and Milk Fat Synthesis. Vet Sci 2019, 6(2).

26. Mezzetti M, Minuti A, Piccioli-Cappelli F, Trevisi E: Inflammatory status and metabolic changes at dry-off in high-yield dairy cows. Italian Journal of Animal Science 2020, 19(1):51-65.

27. Hostmark AT: Serum fatty acid/albumin molar ratio and the risk of diseases. Medical Hypotheses 1995, 44(6):539-541.

28. Celi P, Merlo M, Barbato O, Gabai G: Relationship between oxidative stress and the success of artificial insemination in dairy cows in a pasture-based system. Veterinary journal (London, England : 1997) 2012, 193(2):498-502.

29. Deng Y, Pang Q, Miao R-C, Chen W, Zhou Y-Y, Bi J-B et al: Prognostic significance of pretreatment albumin/globulin ratio in patients with hepatocellular carcinoma. Onco Targets Ther 2016, 9:5317-5328.

30. Stark J: Interpretation of BUN and serum creatinine. An interactive exercise. Critical care nursing clinics of North America 1998, 10(4):491-496.

31. Lin J, Denker BM: Azotemia and urinary abnormalities. In: Harrison's principles of internal medicine. Edited by Kasper DL, vol. 19. New York: McGraw Hill Education; 2015: 289-295.

32. Jahan N, Minuti A, Trevisi E: Assessment of immune response in periparturient dairy cows using ex vivo whole blood stimulation assay with lipopolysaccharides and carrageenan skin test. Veterinary Immunology and Immunopathology 2015, 165(3):119-126. 
33. Rosa F, Osorio JS, Trevisi E, Yanqui-Rivera F, Estill CT, Bionaz M: 2,4-Thiazolidinedione Treatment Improves the Innate Immune Response in Dairy Goats with Induced Subclinical Mastitis. PPAR Res 2017, 2017:7097450.

34. Swanson TJ, Hammer CJ, Luther JS, Carlson DB, Taylor JB, Redmer DA et al: Effects of gestational plane of nutrition and selenium supplementation on mammary development and colostrum quality in pregnant ewe lambs. J Anim Sci 2008, 86(9):2415-2423.

35. Vonnahme Ka, Wienhold CM, Borowicz PP, Neville TL, Redmer Da, Reynolds LP et al: Supranutritional selenium increases mammary gland vascularity in postpartum ewe lambs. Journal of dairy science 2011, 94(6):2850-2858.

36. Gong J, Ni L, Wang D, Shi B, Yan S: Effect of dietary organic selenium on milk selenium concentration and antioxidant and immune status in midlactation dairy cows. Livestock Science 2014, 170:84-90.

37. Séboussi R, Tremblay GF, Ouellet V, Chouinard PY, Chorfi Y, Bélanger G et al: Selenium-fertilized forage as a way to supplement lactating dairy cows. Journal of Dairy Science 2016, 99(7):5358-5369.

38. Ran L, Wu X, Shen X, Zhang K, Ren F, Huang K: Effects of selenium form on blood and milk selenium concentrations, milk component and milk fatty acid composition in dairy cows. Journal of the Science of Food and Agriculture 2010, 90(13):2214-2219.

39. Dodge ML, Wander RC, Xia Y, Butler JA, Whanger PD: Glutathione peroxidase activity modulates fatty acid profiles of plasma and breast milk in Chinese women. Journal of Trace Elements in Medicine and Biology 1999, 12(4):221-230.

40. Zoidis E, Seremelis I, Kontopoulos N, Danezis GP: Selenium-Dependent Antioxidant Enzymes: Actions and Properties of Selenoproteins. Antioxidants (Basel, Switzerland) 2018, 7(5):66.

41. Khalili M, Chamani M, Amanlou H, Nikkhah A, Sadeghi AA: Effects of different sources of selenium supplementation on antioxidant indices, biochemical parameters, thyroid hormones and Se status in transition cows. Acta Scientiarum Animal Sciences 2019, 41.

42. Zahrazadeh M, Riasi A, Farhangfar H, Mahyari SA: Effects of close-up body condition score and selenium-vitamin $\mathrm{E}$ injection on lactation performance, blood metabolites, and oxidative status in high-producing dairy cows. Journal of Dairy Science 2018, 101(11):10495-10504.

43. Busato S, Bionaz M: Selenium-biofortified alfalfa hay supplementation modulates liver and macrophage gene expression in periparturient dairy cows. J Dairy Sci 2020, 103(Suppl. 1):124.

44. Weiner ID, Mitch WE, Sands JM: Urea and Ammonia Metabolism and the Control of Renal Nitrogen Excretion. Clinical Journal of the American Society of Nephrology 2015, 10(8):1444-1458.

45. Schutz Y: Protein turnover, ureagenesis and gluconeogenesis. Int J Vitam Nutr Res 2011, 81(2-3):101-107.

46. Kim J, Van Soest PJ, Combs GF, Jr.: Studies on the effects of selenium on rumen microbial fermentation in vitro. Biol Trace Elem Res 1997, 56(2):203-213.

47. Wei JY, Wang J, Liu W, Zhang KZ, Sun P: Short communication: Effects of different selenium supplements on rumen fermentation and apparent nutrient and selenium digestibility of mid-lactation dairy cows. Journal of Dairy Science 2019, 102(4):3131-3135.

48. Abdo KM: National Toxicology Program Toxicity Report Series Number 38 NTP Technical Report on Toxicity Studies of Sodium Selenate and Sodium Selenite Administered in Drinking Water to F344/N Rats and B6C3F 1 Mice. 1994.

49. Jia Y, Son K, Burris WR, Bridges PJ, Matthews JC: Forms of selenium in vitamin-mineral mixes differentially affect serum alkaline phosphatase activity, and serum albumin and blood urea nitrogen concentrations, of steers grazing endophyte-infected tall fescue. J Anim Sci 2019, 97(6):2569-2582.

50. Kamada $\mathrm{H}$ : Effects of selenium-rich yeast supplementation on the plasma progesterone levels of postpartum dairy cows. AsianAustralasian journal of animal sciences 2017, 30(3):347-354.

51. Sordillo LM: Selenium-dependent regulation of oxidative stress and immunity in periparturient dairy cattle. Vet Med Int 2013, 2013:154045.

52. Witko-Sarsat V, Friedlander M, Capeillère-Blandin C, Nguyen-Khoa T, Nguyen AT, Zingraff J et al: Advanced oxidation protein products as a novel marker of oxidative stress in uremia. Kidney International 1996, 49(5):1304-1313.

53. Witko-Sarsat V: Advanced oxidation protein products as a novel molecular basis of oxidative stress in uraemia. Nephrology Dialysis Transplantation 1999, 14(90001):76-78.

54. Gabai G, De Luca E, Miotto G, Zin G, Stefani A, Da Dalt L et al: Relationship between Protein Oxidation Biomarkers and Uterine Health in Dairy Cows during the Postpartum Period. Antioxidants (Basel, Switzerland) 2019, 8(1):21.

55. Celi P: Oxidative Stress in Ruminants. In: Studies on Veterinary Medicine. Edited by Mandelker L, Vajdovich P. Totowa, NJ: Humana Press; 2011: 191-231.

Page $11 / 18$ 
56. Bordignon M, Da Dalt L, Marinelli L, Gabai G: Advanced oxidation protein products are generated by bovine neutrophils and inhibit free radical production in vitro. Veterinary Journal 2014, 199(1):162-168.

57. Witko-Sarsat V, Gausson V, Descamps-Latscha B: Are advanced oxidation protein products potential uremic toxins? Kidney Int Supp/2003(84):S11-14.

58. Kojouri GA, Sadeghian S, Mohebbi A, Mokhber Dezfouli MR: The effects of oral consumption of selenium nanoparticles on chemotactic and respiratory burst activities of neutrophils in comparison with sodium selenite in sheep. Biol Trace Elem Res 2012, 146(2):160-166.

59. Capeillère-Blandin C, Gausson V, Nguyen AT, Descamps-Latscha B, Drüeke T, Witko-Sarsat V: Respective role of uraemic toxins and myeloperoxidase in the uraemic state. Nephrol Dial Transplant 2006, 21(6):1555-1563.

60. Gutteridge JM: Antioxidant properties of the proteins caeruloplasmin, albumin and transferrin. A study of their activity in serum and synovial fluid from patients with rheumatoid arthritis. Biochim Biophys Acta 1986, 869(2):119-127.

61. Anraku M, Chuang VT, Maruyama T, Otagiri M: Redox properties of serum albumin. Biochim Biophys Acta 2013, 1830(12):54655472 .

62. Iwao Y, Anraku M, Hiraike M, Kawai K, Nakajou K, Kai T et al: The structural and pharmacokinetic properties of oxidized human serum albumin, advanced oxidation protein products (AOPP). Drug Metab Pharmacokinet 2006, 21(2):140-146.

63. Bourdon E, Loreau N, Lagrost L, Blache D: Differential effects of cysteine and methionine residues in the antioxidant activity of human serum albumin. Free Radic Res 2005, 39(1):15-20.

64. Juniper DT, Rymer C, Briens M: Bioefficacy of hydroxy-selenomethionine as a selenium supplement in pregnant dairy heifers and on the selenium status of their calves. Journal of Dairy Science 2019, 102(8):7000-7010.

65. Mir AA, Goyal B, Datta SK, Ikkurthi S, Pal A: Comparison Between Measured and Calculated Free Calcium Values at Different Serum Albumin Concentrations. $J$ Lab Physicians 2016, 8(2):71-76.

66. Martín-Tereso J, Martens $\mathrm{H}$ : Calcium and magnesium physiology and nutrition in relation to the prevention of milk fever and tetany (dietary management of macrominerals in preventing disease). Vet Clin North Am Food Anim Pract 2014, 30(3):643-670.

67. Roche JR, Burke CR, Crookenden MA, Heiser A, Loor JL, Meier S et al: Fertility and the transition dairy cow. Reproduction, Fertility and Development 2017, 30(1):85-100.

68. Kaushal N, Hegde S, Lumadue J, Paulson RF, Prabhu KS: The Regulation of Erythropoiesis by Selenium in Mice. Antioxidants \& Redox Signaling 2010, 14(8):1403-1412.

69. Faixová Z, Faix Š, Leng L', Váczi P, Maková Z, Szabóová R: Haematological, Blood and Rumen Chemistry Changes in Lambs Following Supplementation with Se-yeast. Acta Veterinaria Brno 2007, 76(1):3-8.

70. Mohanty J, Nagababu E, Rifkind J: Red blood cell oxidative stress impairs oxygen delivery and induces red blood cell aging. Frontiers in Physiology 2014, 5(84).

71. Rotruck JT, Pope AL, Ganther HE, Swanson AB, Hafeman DG, Hoekstra WG: Selenium: Biochemical Role as a Component of Glutathione Peroxidase. Science 1973, 179(4073):588-590.

\section{Tables}

Table 1. Performance of Jersey ( $n=5 /$ group) and Holstein ( $n=4 /$ group) pregnant dairy heifers supplemented with $1 \%$ BW of Sebiofortified alfalfa hay (Sel) or no biofortified alfalfa hay (Ctr) from 40 days prior expected parturition to 14 days after calving 


\begin{tabular}{|c|c|c|c|c|c|c|c|c|c|c|c|c|}
\hline Parameter & Holstein & & Jersey & & & P-valu & & & & & & \\
\hline & Ctr & $\mathrm{Sel}$ & Ctr & Sel & SEM & Se & $B r$ & $T$ & $\operatorname{SexBr}$ & SexT & $B r \times T$ & SexBrxT \\
\hline BW kg & 548.6 & 554.7 & 469.1 & 463.1 & 19.8 & 0.99 & $<0.01$ & $<0.01$ & 0.75 & 0.12 & 0.57 & 0.20 \\
\hline BCS & 2.97 & 2.94 & 3.18 & 3.21 & 0.09 & 0.96 & 0.02 & 0.03 & 0.72 & 0.24 & 0.87 & 0.72 \\
\hline $\mathrm{DMI} \mathrm{kg} / \mathrm{d}^{2}$ & 12.2 & 12.9 & 11.3 & 11.2 & 0.67 & 0.65 & 0.06 & $<0.01$ & 0.58 & 0.75 & 0.74 & 0.93 \\
\hline DMI/BW \%² & 2.23 & 2.31 & 2.35 & 2.39 & 0.13 & 0.64 & 0.45 & $<0.01$ & 0.85 & 0.88 & 0.97 & 0.98 \\
\hline $\begin{array}{l}\text { Milk Yield } \\
\mathrm{Kg} / \mathrm{d}^{3}\end{array}$ & 21.2 & 23.7 & 20.2 & 17.7 & 1.67 & 0.99 & 0.03 & $<0.01$ & 0.11 & 0.51 & 0.89 & 0.82 \\
\hline $\begin{array}{l}\text { Milk Yield } \\
\mathrm{Kg} / \mathrm{d}^{4}\end{array}$ & 27.0 & 28.5 & 25.0 & 24.0 & 1.19 & 0.79 & 0.02 & 0.01 & 0.34 & 0.82 & 0.46 & 0.07 \\
\hline $\mathrm{ECM} \mathrm{kg} / \mathrm{d}^{5}$ & 17.7 & 19.5 & 20.7 & 17.0 & 2.64 & 0.68 & 0.92 & 0.04 & 0.24 & 0.84 & 0.95 & 0.90 \\
\hline $\mathrm{FCM} \mathrm{kg} / \mathrm{d}^{6}$ & 16.3 & 18.3 & 20.4 & 16.7 & 3.09 & 0.75 & 0.63 & 0.03 & 0.30 & 0.85 & 0.88 & 0.75 \\
\hline FPCM kg/d ${ }^{7}$ & 18.2 & 19.9 & 20.9 & 17.4 & 2.64 & 0.68 & 0.96 & 0.04 & 0.26 & 0.83 & 0.96 & 0.91 \\
\hline $\begin{array}{l}\text { Dairy } \\
\text { Efficiency }^{8}\end{array}$ & 1.27 & 1.45 & 1.52 & 1.48 & 0.09 & 0.44 & 0.11 & $<0.01$ & 0.21 & 0.57 & 0.69 & 0.19 \\
\hline \multicolumn{13}{|l|}{$\begin{array}{l}\text { Milk } \\
\text { composition }^{9}\end{array}$} \\
\hline Fat $\%$ & 2.79 & 2.82 & 3.98 & 3.45 & 0.56 & 0.64 & 0.11 & 0.23 & 0.61 & 0.91 & 0.20 & 0.47 \\
\hline Protein \% & 3.64 & 3.73 & 3.85 & 3.82 & 0.17 & 0.84 & 0.37 & $<0.01$ & 0.71 & 0.32 & 0.66 & 0.30 \\
\hline Lactose \% & 4.58 & 4.65 & 4.58 & 4.47 & 0.11 & 0.87 & 0.41 & $<0.01$ & 0.40 & 0.68 & 0.34 & 0.73 \\
\hline SNF \% & 9.35 & 9.44 & 9.45 & 9.33 & 0.15 & 0.93 & 0.99 & $<0.01$ & 0.47 & 0.56 & 0.65 & 0.25 \\
\hline $\operatorname{sCC}\left(\log _{2}\right)$ & 7.06 & 5.07 & 7.00 & 7.71 & 0.73 & 0.38 & 0.09 & $<0.01$ & 0.08 & 0.37 & 0.79 & 0.37 \\
\hline MUNN mg/dl & 13.2 & 13.6 & 17.0 & 17.2 & 1.84 & 0.88 & 0.05 & 0.07 & 0.94 & 0.96 & 0.07 & 0.40 \\
\hline Fat $\mathrm{g} / \mathrm{d}$ & 516.7 & 609.2 & 819.7 & 643.3 & 178.4 & 0.78 & 0.28 & 0.09 & 0.38 & 0.90 & 0.81 & 0.55 \\
\hline Protein g/d & 828.8 & 898.3 & 766.3 & 663.7 & 59.3 & 0.75 & 0.01 & 0.12 & 0.11 & 0.76 & 0.32 & 0.63 \\
\hline Lactose g/d & $969.5^{\mathrm{ab}} 5$ & $1112.3^{a}$ & $927.9^{a b}$ & $788.2^{b}$ & 76.8 & 0.98 & 0.02 & $<0.01$ & 0.05 & 0.48 & 0.61 & 0.78 \\
\hline SNF g/d & 2013.5 & 2262.8 & 1922.4 & 1669.2 & 136.7 & 0.99 & 0.02 & 0.01 & 0.06 & 0.48 & 0.92 & 0.47 \\
\hline MUNN g/d & 2.73 & 3.32 & 3.85 & 3.14 & 0.67 & 0.92 & 0.44 & $<0.01$ & 0.30 & 0.56 & 0.09 & 0.89 \\
\hline $\begin{array}{l}\text { Conductivity } \\
\text { mS }\end{array}$ & 8.95 & 8.97 & 8.93 & 9.05 & 0.18 & 0.71 & 0.89 & $<0.01$ & 0.80 & 0.97 & 0.93 & 0.73 \\
\hline $\begin{array}{l}\text { Activity } \\
\text { steps/h }\end{array}$ & 119.8 & 127.2 & 152.4 & 147.8 & 8 & 0.89 & 0.02 & 0.10 & 0.54 & 0.93 & 0.62 & 0.68 \\
\hline
\end{tabular}

${ }^{1} \mathrm{Se}=$ Selenium biofortified alfalfa treatment; $\mathrm{Br}=$ Breed; $\mathrm{T}=\mathrm{Time}$

${ }^{2}$ The data were analyzed as weekly average

${ }^{3}$ Up to14 day post-partum with daily milk yield

${ }^{4}$ Up to 120 days post-partum with daily milk yield averaged weekly 
${ }^{5}$ Energy Corrected Milk = kg milk*(38.3×kg fat+24.2×kg protein+15.71×kg lactose+20.7)/3140 (Sjaunja et al., 1991).

${ }^{6}$ Fat-corrected Milk $=0.4 \times \mathrm{kg}$ milk $+15 \times \mathrm{kg}$ fat (Gaafar et al., 2010).

${ }^{7}$ Fat and Protein corrected Milk $=[0.337+0.116 \times$ fat $(\%)+0.06 \times$ protein $(\%)] \times$ kg milk (van Hoeij et al., 2017$)$.

${ }^{8}$ FCM/DMI

${ }^{9}$ SNF = Solid Non-Fat; SCC $=$ Somatic Cell Count in $10^{3}$ cell $/ \mathrm{mL} ;$ MUNN = Milk Urea Nitrogen

Table 2. Plasma parameters in Jersey and Holstein pregnant heifers supplemented with $1 \%$ BW of Se-biofortified alfalfa hay (Sel) or no biofortified alfalfa hay (Ctr) from 40 days prior expected parturition to 14 days after calving 


\begin{tabular}{|c|c|c|c|c|c|c|c|c|c|c|}
\hline \multirow[t]{2}{*}{ Parameter $^{1}$} & \multirow{2}{*}{$\begin{array}{l}\text { Holstein } \\
\text { Ctr }\end{array}$} & \multicolumn{2}{|c|}{ Jersey } & \multicolumn{4}{|c|}{ P-value ${ }^{2}$} & \multirow[b]{2}{*}{$\operatorname{Sex} T$} & \multirow[b]{2}{*}{$S e \times B r$} & \multirow[b]{2}{*}{$\operatorname{SexBr\times T}$} \\
\hline & & Sel & Ctr & Sel & SEM & $\mathrm{Se}$ & $B r$ & & & \\
\hline \multicolumn{10}{|l|}{ Metabolic status } & \multirow[b]{2}{*}{0.65} \\
\hline NEFA mmol/l & 0.48 & 0.58 & 0.61 & 0.53 & 0.12 & 0.92 & 0.71 & 0.93 & 0.44 & \\
\hline NEFAVAlbumin ${ }^{3}$ & 0.91 & 1.07 & 1.18 & 0.80 & 0.18 & 0.51 & 0.67 & 0.96 & 0.14 & 0.77 \\
\hline BHB mmol/l & 0.57 & 0.60 & 0.65 & 0.70 & 0.08 & 0.65 & 0.28 & 0.31 & 0.88 & 0.45 \\
\hline Glucose mmol/l & 4.36 & 4.36 & 4.24 & 4.22 & 0.11 & 0.90 & 0.23 & 0.22 & 0.90 & 0.79 \\
\hline Cholesterol mmol/l & 2.54 & 2.65 & 1.96 & 1.99 & 0.24 & 0.77 & 0.02 & 0.97 & 0.85 & 0.61 \\
\hline Urea mmol/l & 5.24 & 5.75 & 5.17 & 6.11 & 0.37 & 0.06 & 0.67 & 0.56 & 0.54 & 0.98 \\
\hline \multicolumn{11}{|l|}{ Inflammatory status } \\
\hline Ceruloplasmin $\mu \mathrm{mol} / \mathrm{l}$ & 2.52 & 2.65 & 2.90 & 2.96 & 0.30 & 0.73 & 0.23 & 0.64 & 0.90 & 0.61 \\
\hline Haptoglobin g/l & 0.64 & 0.77 & 0.66 & 0.67 & 0.09 & 0.42 & 0.65 & 0.76 & 0.50 & 0.06 \\
\hline Myeloperoxidase U/L & 402.9 & 468.1 & 394.0 & 426.2 & 29.1 & 0.10 & 0.37 & 0.79 & 0.56 & 0.46 \\
\hline Albumin $\mathrm{g} / \mathrm{l}$ & 35.5 & 36.1 & 36.1 & 37.5 & 0.85 & 0.26 & 0.22 & 0.02 & 0.62 & $<0.01$ \\
\hline Paraoxonase U/ml & 73.5 & 79.2 & 74.1 & 74.8 & 5.4 & 0.54 & 0.70 & 0.61 & 0.63 & 0.94 \\
\hline \multicolumn{11}{|l|}{ Liver status } \\
\hline AST/GOT U/L & 99.4 & 99.2 & 98.4 & 92.8 & 4.4 & 0.50 & 0.39 & 0.99 & 0.53 & 0.93 \\
\hline GGT U/L & 22.3 & 23.5 & 22.0 & 21.4 & 1.7 & 0.83 & 0.46 & 0.11 & 0.58 & 0.97 \\
\hline ALP U/L & 69.3 & 74.1 & 64.6 & 58.6 & 11.2 & 0.95 & 0.36 & 0.36 & 0.62 & 0.05 \\
\hline Bilirubin $\mu \mathrm{mol} / \mathrm{l}$ & 4.16 & 4.56 & 3.52 & 3.41 & 0.64 & 0.81 & 0.16 & 0.82 & 0.67 & 0.94 \\
\hline \multicolumn{11}{|l|}{ Oxidative status } \\
\hline $\mathrm{ROMt} \mathrm{mg} \mathrm{H}_{2} \mathrm{O}_{2} / 100 \mathrm{ml}$ & 14.8 & 15.3 & 14.6 & 15.5 & 1.1 & 0.51 & 0.98 & 0.72 & 0.81 & 0.77 \\
\hline Thiol Groups $\mu \mathrm{mol} / /$ & 335.3 & 357.3 & 352.7 & 359.9 & 14.4 & 0.30 & 0.47 & 0.19 & 0.60 & 0.65 \\
\hline FRAP $\mu \mathrm{mol} / \mathrm{I}$ & 149.4 & 134.8 & 139.4 & 132.5 & 8.7 & 0.22 & 0.47 & 0.38 & 0.65 & 0.53 \\
\hline AOPP $\mu \mathrm{mol} / \mathrm{I}$ & 34.3 & 43.0 & 32.5 & 35.8 & 1.9 & $<0.01$ & 0.02 & 0.34 & 0.15 & 0.96 \\
\hline AOPP/Albumin & 0.97 & 1.15 & 0.91 & 0.94 & 0.05 & 0.05 & 0.01 & 0.67 & 0.17 & 0.94 \\
\hline \multicolumn{11}{|l|}{ Minerals } \\
\hline Ca mmol/l & 2.45 & 2.46 & 2.43 & 2.47 & 0.04 & 0.44 & 0.90 & 0.39 & 0.70 & $<0.01$ \\
\hline Free Ca mmol//4 & 1.21 & 1.21 & 1.19 & 1.20 & 0.01 & 0.79 & 0.36 & 0.36 & 0.71 & 0.03 \\
\hline Mg mmol/l & 0.98 & 0.92 & 1.09 & 1.07 & 0.03 & 0.20 & $<0.01$ & 0.72 & 0.58 & $<0.01$ \\
\hline \multicolumn{11}{|l|}{ Kidney Function } \\
\hline Creatinine $\mu \mathrm{mol} / \mathrm{l}$ & 100.2 & 94.9 & 86.1 & 88.2 & 2.5 & 0.52 & $<0.01$ & 0.32 & 0.13 & 0.21 \\
\hline Urea/Creatinine & 52.3 & 60.2 & 59.7 & 69.3 & 3.63 & 0.02 & 0.03 & 0.46 & 0.80 & 0.98 \\
\hline \multicolumn{11}{|l|}{ Other parameters } \\
\hline Hematocrit V/V\% & 33.8 & 35.8 & 32.9 & 34.0 & 0.70 & 0.04 & 0.07 & 0.62 & 0.51 & 0.85 \\
\hline Total protein $\mathbf{g} / \mathbf{l}$ & 74.0 & 76.7 & 71.0 & 74.5 & 1.49 & 0.08 & 0.04 & 0.78 & 0.75 & 0.63 \\
\hline Globulin g/l & 38.5 & 35.3 & 34.8 & 37.0 & 1.58 & 0.51 & 0.35 & 0.33 & 0.08 & 0.64 \\
\hline
\end{tabular}




\begin{tabular}{|lllllllllll|}
\hline Albumin/Globulin & 0.94 & 1.04 & 1.06 & 1.02 & 0.05 & 0.56 & 0.36 & 0.36 & 0.18 & 0.50 \\
\hline
\end{tabular}

${ }^{1}$ NEFA = Non-esterified fatty acids; BHB: $\beta$ - hydroxybutyric acid; AST/GOT: Aspartate amino-transferase; GGT: $\gamma$-glutamyl transferase; ALP: Alkaline phosphatase; ROMt: Total reactive oxygen metabolites; FRAP: Ferric reducing antioxidant power; AOPP: Advanced oxidation protein products

${ }^{2} \mathrm{Se}=$ Selenium biofortified alfalfa treatment; $\mathrm{Br}=\mathrm{Breed} ; \mathrm{T}=\mathrm{Time}$

${ }^{3} \mathrm{NEFA} /$ Albumin ratio $=\mathrm{mM}$ NEFA $/ \mathrm{mM}$ Albumin à (Albumin g/L/(Albumin MW $\left.\left.[66,463] \times 1000\right)\right)$

${ }^{4}$ Free calcium was calculated as previously described [65] using the Orrell adjusted Ca as follow (Free Ca $=(\mathrm{Ca} \mathrm{mmol} / \mathrm{I}+0.0176$ * $(34-$ albumin $\mathrm{g} / \mathrm{L}) / 2$

Table 3. Carrageenan skin test (CST), phagocytosis, and leukocytes differential in Jersey and Holstein pregnant dairy heifers supplemented with $1 \%$ BW of Se-biofortified alfalfa hay (Sel) or no biofortified alfalfa hay (Ctr) from 40 days prior expected parturition to 14 days after calving 


\begin{tabular}{|c|c|c|c|c|c|c|c|c|c|c|c|}
\hline \multirow[t]{2}{*}{ Parameters } & \multicolumn{2}{|c|}{ Holstein } & \multicolumn{3}{|c|}{ Jersey } & \multicolumn{6}{|c|}{ P-value ${ }^{1}$} \\
\hline & Ctr & Sel & Ctr & Sel & SEM* & Se & $B r$ & $\operatorname{Sex} T$ & $\mathrm{Se} \times \mathrm{Br}$ & $B r \times T$ & $\operatorname{Se} \times B r \times T$ \\
\hline \multicolumn{12}{|l|}{ CST } \\
\hline Day 2 mm & 1.13 & 1.29 & 1.30 & 1.46 & 0.30 & 0.57 & 0.54 & 0.81 & 0.99 & 0.92 & 0.97 \\
\hline Day 9 mm & 1.82 & 1.63 & 1.57 & 2.07 & 0.35 & 0.63 & 0.77 & 0.71 & 0.30 & 0.56 & 0.34 \\
\hline $\mathrm{AUC}^{2}$ & 11.7 & 11.6 & 11.7 & 13.6 & 2.06 & 0.65 & 0.59 & 0.83 & 0.61 & 0.93 & 0.83 \\
\hline \multicolumn{12}{|l|}{ Phagocytosis (\%) } \\
\hline Leukocytes & 25.4 & 34.8 & 20.1 & 21.5 & 7.11 & 0.36 & 0.13 & 0.82 & 0.50 & 0.73 & 0.41 \\
\hline Granulocyte $^{3}$ & 50.4 & 71.2 & 40.9 & 43.7 & 14.2 & 0.32 & 0.13 & 0.60 & 0.45 & 0.92 & 0.48 \\
\hline Monocytes ${ }^{4}$ & 78.8 & 78.2 & 75.6 & 68.9 & 16.3 & 0.80 & 0.66 & 0.33 & 0.83 & 0.01 & 0.61 \\
\hline PMN+Monocytes 5 & 50.1 & 67.5 & 39.1 & 40.8 & 11.4 & 0.34 & 0.07 & 0.58 & 0.43 & 0.51 & 0.19 \\
\hline \multicolumn{12}{|l|}{ Differential (\%) } \\
\hline Granulocytes $^{3}$ & 31.6 & 35.3 & 33.7 & 33.1 & 4.60 & 0.69 & 0.99 & 0.56 & 0.59 & 0.34 & 0.84 \\
\hline PMN+Monocyte 5 & 47.5 & 55.2 & 51.5 & 46.4 & 4.91 & 0.77 & 0.58 & 0.97 & 0.15 & 0.54 & 0.94 \\
\hline Lymphocytes $^{5}$ & 52.5 & 45.1 & 48.6 & 53.5 & 4.94 & 0.77 & 0.60 & 0.96 & 0.17 & 0.51 & 0.96 \\
\hline Monocytes ${ }^{4}$ & 1.56 & 0.56 & 0.76 & 1.82 & 0.92 & 0.97 & 0.78 & 0.25 & 0.22 & 0.30 & 0.76 \\
\hline \multicolumn{12}{|c|}{ Leukocytes $\times 1000 /\left.\mu\right|^{6}$} \\
\hline Total ${ }^{\#}$ & 13.6 & 14.4 & 11.3 & 10.6 & 1.4 & 0.50 & $<0.01$ & 0.19 & 0.87 & 0.06 & 0.02 \\
\hline Granulocytes ${ }^{3}$ & 4.18 & 3.08 & 3.80 & 3.34 & 0.78 & 0.21 & 0.92 & 0.99 & 0.60 & 0.38 & 0.21 \\
\hline PMN+Monocyte 5 & 5.64 & 5.44 & 4.85 & 4.54 & 0.76 & 0.67 & 0.17 & 0.64 & 0.92 & $<0.01$ & 0.54 \\
\hline Lymphocytes $^{5}$ & 6.92 & 4.34 & 5.50 & 5.58 & 1.32 & 0.26 & 0.93 & 0.84 & 0.24 & 0.09 & 0.55 \\
\hline
\end{tabular}

${ }^{1} \mathrm{Se}=$ Selenium biofortified alfalfa treatment; $\mathrm{Br}=\mathrm{Breed} ; \mathrm{T}=\mathrm{Time}$

${ }^{2}$ Area under the curve of skin thickness from day 0 to 9 .

${ }^{3}$ Cells positive to $\mathrm{CH} 138 \mathrm{~A}$ antibody

${ }^{4}$ Cells positive to CAM36 antibody

${ }^{5}$ Cells gated manually

${ }^{6} \mathrm{Absolute}$ number of each category of leukocytes using differential (\%)

\#The leukocytes total count was measured during the whole trial while the flow cytometer analysis was performed only at $-10,4$, and 14 DIM. The total leukocytes was also corrected by the baseline.

*Highest SEM

Figures 

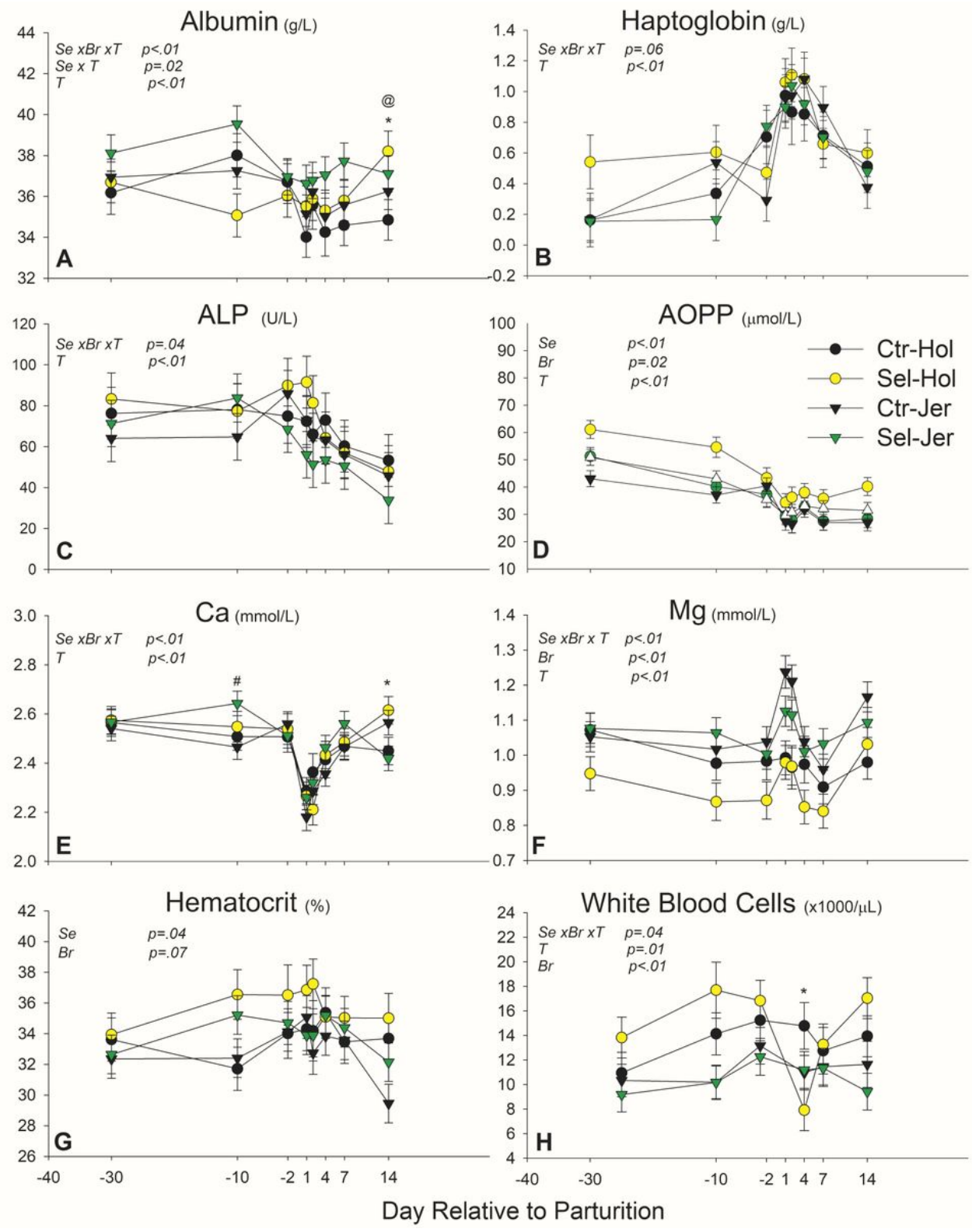

\section{Figure 1}

Significantly affected blood parameters. Blood parameters that were significantly $(\mathrm{p} \leq .05)$ affected by feeding cows with Se biofortified alfalfa (Se) or the interaction between Se, breed (Br), and Time in Jersey (Jer; $n=5 /$ group) and Holstein (Hol; $n=4 /$ group) pregnant dairy heifers supplemented with $1 \%$ BW of Se-biofortified alfalfa hay (Sel) or no biofortified alfalfa hay (Ctr) from 40 days prior expected parturition to 14 days after calving. Reported in the graph are the $\mathrm{P}$-value of the overall effect of $\mathrm{Se}, \mathrm{Time}, \mathrm{Br}$, and their interactions. * and \# denote difference with $\mathrm{P} \leq 0.05$ between groups at each time point in Holstein and Jersey cows, respectively, when significant $(P \leq 0.05)$ SexBrxTime was detected. @ denotes a significant effect in a time point when significant $(P \leq 0.05)$ SexTime interaction was detected.

\section{Supplementary Files}

This is a list of supplementary files associated with this preprint. Click to download.

- AdditionalFile1.docx

- AdditionalFile2.docx

- AdditionalFile3.xlsx 